First Peoples Child \& Family Review

A Journal on Innovation and Best Practices in Aboriginal Child Welfare Administration,

Research, Policy \& Practice

\title{
The Politics of Policy Development to End Obesity for Aboriginal Youth in the Educational Environment
}

\section{Shelley Spurr}

Volume 3, Number 3, 2007

URI: https://id.erudit.org/iderudit/1069398ar

DOI: https://doi.org/10.7202/1069398ar

See table of contents

Publisher(s)

First Nations Child and Family Caring Society of Canada

\section{ISSN}

1708-489X (print)

2293-6610 (digital)

Explore this journal

Cite this article

Spurr, S. (2007). The Politics of Policy Development to End Obesity for Aboriginal Youth in the Educational Environment. First Peoples Child \& Family Review, 3(3), 72-83. https://doi.org/10.7202/1069398ar
Article abstract

Canada, a country of considerable wealth and resources, has one of the highest standards of living in the world. This country is politically organized as a democracy that is supportive of political and civil freedoms, yet inequalities among certain populations prevail. In general, Aboriginal people experience poorer economic, social, and environmental conditions than those of non-Aboriginal people (Canadian Population Health Initiative, 2005) and lower involvement in political and civil activity. This report also illustrates the inferior health status among Aboriginal people. Within the school system, an educational policy can serve to address an inequality. Hence, the purpose of the paper is to apply the tools outlined by Deborah Stone in her book, Policy Parodox: The Art of Political Decision Making (2002), to demonstrate why I believe school policies should be developed to prevent obesity among Aboriginal youth, to understand the politics of implementing these policies and to analyze and critique the ideas from hypothesized political opponents. Addressing these injustices provides recognition of the racism in present-day educational policy decision-making processes, which can result in more significant progress toward an equal and just society which ensures the health of Aboriginal peoples and successive generations.
This document is protected by copyright law. Use of the services of Érudit (including reproduction) is subject to its terms and conditions, which can be viewed online.

https://apropos.erudit.org/en/users/policy-on-use/ 


\title{
The Politics of Policy Development to End Obesity for Aboriginal Youth in the Educational Environment
}

\author{
Shelley Spurra
}

${ }^{a}$ Assistant Professor, College of Nursing, University of Saskatchewn, SK, Canada. Shelley is currently enrolled in the $\mathrm{PhD}$ studies in Education Administration focussing on promotion of wellness in adolescents.

Canada, a country of considerable wealth and resources, has one of the highest standards of living in the world. This country is politically organized as a democracy which is supportive of political and civil freedoms, yet inequalities among certain populations prevail. Aboriginal people continue to have shorter life expectancy, lower educational attainment, and lower average annual incomes than do other Canadians (Cooke, Beavon, \& McHardy, 2004). There are significant social and economic disparities among Aboriginal peoples, and these disparities have had significant impact on the lives and health of their children and families (Canadian Population Health Initiative, 2005). Within the school system, educational policy-making can serve to address inequalities. Hence, the purpose of this paper is to highlight the tools in Deborah Stone's book, Policy Paradox: The Art of Political Decision Making (2002), to demonstrate why I believe policies should be developed to combat obesity in a school, to understand the politics of implementing these policies and to analyze and critique the ideas from hypothesized political opponents.

This paper begins by defining obesity and then provides evidence of its increasing rates both among non-Aboriginal and Aboriginal young

Questions or correspondence concerning this article may be addressed to:

shelley.spurr@usask.ca

\begin{abstract}
Canada, a country of considerable wealth and resources, has one of the highest standards of living in the world. This country is politically organized as a democracy that is supportive of political and civil freedoms, yet inequalities among certain populations prevail. In general, Aboriginal people experience poorer economic, social, and environmental conditions than those of non-Aboriginal people (Canadian Population Health Initiative, 2005) and lower involvement in political and civil activity. This report also illustrates the inferior health status among Aboriginal people. Within the school system, an educational policy can serve to address an inequality. Hence, the purpose of the paper is to apply the tools outlined by Deborah Stone in her book, Policy Parodox: The Art of Political Decision Making (2002), to demonstrate why I believe school policies should be developed to prevent obesity among Aboriginal youth, to understand the politics of implementing these policies and to analyze and critique the ideas from hypothesized political opponents. Addressing these injustices provides recognition of the racism in present-day educational policy decision-making processes, which can result in more significant progress toward an equal and just society which ensures the health of Aboriginal peoples and successive generations.
\end{abstract}

people. The interventive goals, as outlined by Stone (2002) are then defined and assessed through the following concepts: equity, security and liberty. Working to achieve these goals becomes a political struggle as each of these concepts suggests different interpretations and has some inherent and associated ambiguities. Next, I examine the problems associated with this policy initiative. Defining the problem can also develop into a political struggle as my strategic representation of the situation will almost certainly bring about controversy and opposition. The policy problems discussed include causes, decisions, power and interests. I identify some potential solutions to the problems presented, and lastly, present some future research implications. 


\section{Introduction}

In writing this paper, I have chosen to reference Deborah Stone's book Policy Paradox: The Art of Political Decision Making (2002) (hereafter the "Policy Paradox") 1 as it offers a theoretical framework for policy analysis that accepts politics as a valuable and creative process, that is true to the diversity of the human mind, and that renders more visible the paradoxes of policy decisions. Stone wrote that policies include goals, problems and solutions. She created a model of reasoning that shows how decisions should be made in a series of well-defined steps:

1. Identify objectives;

2. Identify alternative courses of action for achieving objectives;

3. Predict the possible consequences of each alternative;

4. Evaluate the possible consequences of each alternative;

5. Select the alternative that maximizes the attainment of objectives (p.8).

Stone's book, Policy Paradox, helped me to think about developing educational policy, understand the politics of the obesity issue particularly among Aboriginal groups, and to analyze and critique arguments that might be expressed by opponents. Similar to Stone (2002), I have framed this paper with the following concepts: goals, problems and solutions.

Like Stone, I believe that policy decisions are highly influenced by personal experiences and values. As a nurse I have worked with Aboriginal children, youth and families, and from this experience I have observed the poverty, discrimination, health disparities, and the general inequalities that continue to exist within the Aboriginal nation. As such, I intend to approach this analysis as someone who knows that, due to racism and discrimination, Aboriginal children and families have suffered many injustices, and that addressing this legacy can result in more significant progress towards an equal and just society with better health outcomes for Aboriginal young people.

Although there are many health concerns among Aboriginal people, this paper focuses on overweight and obesity in Canada considered to be higher in Aboriginal children and youth than in the non-Aboriginal population (Willows, 2005). The development and implementation of effective strategies to prevent obesity is a serious health challenge facing Aboriginal communities today. It is for these reasons that I believe there is an urgent need to examine the complex social processes of developing and implementing health policies designed to prevent obesity in Aboriginal youth.

Obesity issues among Aboriginal youth is multifaceted and as such, the biological, cultural, and social contributions to obesity must be addressed in order to fully understand the problem and develop appropriate interventions (Willows, 2005). However, that depth of analysis is not possible in this paper. Instead, the intent of this paper is to explore political controversies associated with the development of school health policies designed to prevent obesity in an Aboriginal high school.

\section{Background}

In 2005, the principal of Lee Brown High School ${ }^{2}$ approached the University of Saskatchewan with an interest in developing a program to address ongoing health concerns, specifically obesity and Type 2 Diabetes, among the Aboriginal student population. A research partnership between the Lee Brown High School and the University of Saskatchewan was then initiated. The overarching goal of the research partnership was to establish a working relationship with the high school community with the future intent to build capacity in Aboriginal health research, to cultivate relationships with Aboriginal communities, to address the prominent health issue of obesity and to develop an intervention that is derived from the needs and priorities of the communities that successfully address healthy body weights in Aboriginal youth. As a PhD student, I worked with the students and teachers to explore the factors affecting the students' dietary and physical activity behaviours, as well as the staff's visions for future health promotion programs and policies among the parents and student body.

Policy initiatives, such as the proposed health promotion intervention at Lee Brown High School can assist to create and sustain a healthy environment that encourages healthy eating and physical activity among Aboriginal youth (Willows, 2005). Despite this knowledge, I anticipate that there will be 
significant political debate when it comes time to developing policy aimed at preventing obesity among the Aboriginal student population in Lee Brown High School. The major opponent to this initiative would be the Department of Indian and Northern Affairs Development (DIAND) and the local provincial school board. The operators, who manage the funding for the school, may not necessarily oppose the health intervention, but due to fiscal restraints, may decline funding this particular health policy initiative.

\section{OBESITY AND THE ROLE OF SCHOOLS}

\section{The Evidence of Obesity}

In Canada, children and youth are classified as overweight or obese based on their Body Mass Index (BMI), which is a ratio of weight in kilograms to the square of height in metres. In children, international standards for BMI account for normal growth and development by incorporating different age and sex percentiles (Cole, Bellizzi, Flegal, \& Dietz, 2000). The rates of obesity among Canadian children and youth are increasing at alarming rates. To illustrate, Table 1 indicates that over a 15-year period in Canada (between 1981-1996), "the prevalence of overweight and obesity has tripled among boys and doubled among girls" (Tremblay, Katzmarzyk and Willms, 2002, p. 538). This data suggests that not only have children become more overweight in the past few decades, but also, that overweight children have been getting heavier.

\begin{tabular}{|c|c|c|c|c|}
\hline \multicolumn{5}{|c|}{ Table 1} \\
\hline \multicolumn{5}{|c|}{ Summary of Overweight and Obesity in Canada } \\
\hline \multicolumn{5}{|c|}{ Overweight, including Obese } \\
\hline & 1981 & 1996 & 1981 & 1996 \\
\hline Boys & $11 \%$ & $33 \%$ & $2 \%$ & $10 \%$ \\
\hline Girls & $13 \%$ & $27 \%$ & $2 \%$ & $9 \%$ \\
\hline
\end{tabular}

Evidence suggests that Aboriginal children and youth living in Canada have a high rate of overweight and obesity (Willows, 2005, p. 77). As shown in Table 2, Canadian Aboriginal children and youth, aged 419, also have a high prevalence of obesity (based on the data obtained from a study conducted by Young, Dean, Flett and Wood-Steiman, 2000). Another study of childhood obesity in Canada also suggests very high rates of obesity and overweight (i.e., BMI of greater than 85th percentile for age and sex specific reference data) among Aboriginal boys (27.7\%) and girls (33.7\%) (Hanley et al., 2000).

\begin{tabular}{|c|c|c|}
\hline $\begin{array}{l}\text { Moderate-High Levels of } \\
\text { Children and Youth }\end{array}$ & sity in & igina \\
\hline & Female & Male \\
\hline$>85 \%$ (Moderate-Level Obesity) & $64 \%$ & $60 \%$ \\
\hline$>95 \%$ (High-Level Obesity) & $40 \%$ & $34 \%$ \\
\hline
\end{tabular}

Obese children have a greater risk than normal weight children of becoming obese adults and, thus, at greater risk of developing one or more health problems such as type two diabetes mellitus, coronary heart disease, stroke and respiratory disorders (Harris et al., 2002; Janssen et al., 2005; Schwimmer, Burwinkle, $\&$ Varni, 2003). Evidence is accumulating to suggest that Type 2 Diabetes Mellitus (T2DM) is becoming an increasing burden for Aboriginal children and adolescents (Ritenbaugh et al., 2003). Young, Dean, Flett and Wood-Steiman (2000) found that among the Aboriginal children in their study, high fasting glucose and fasting insulin levels were associated with obesity.

\section{The School Environment}

As children spend a large amount of time in school, this environment is considered the most logical venue in which to accommodate and develop school health policies and programs for the prevention and management of obesity (Canadian Population Health Initiative, 2004). School programs and policies designed for prevention and management of obesity can then provide youth with the knowledge and support they need in order to adopt and maintain healthy eating and physical activity behaviours (Briggs, Safaii, \& Beall, 2003). For example, school interventions have been effective for increasing student knowledge and consumption of fruit, fruit juices and vegetables, and decreasing consumption of high sugar beverages and fat intake among young people (Evans \& Sawyer-Morse, 2002; O'Neil \& Nicklas, 2002). Similarly, through participation in school programs, physical activity levels among students have increased while pulse rates, fasting and 30-minute plasma insulin levels have decreased (Dale \& Corbin, 2000; Ritenbaugh et al., 2003). Schools also 
offer opportunities for mentoring and individualized counseling for youth.

Clearly, schools have proven to be a setting where changes in healthy eating, physical activity behaviours and knowledge can occur, and would be an appropriate environment to begin working to prevent obesity among Aboriginal children and youth.

\section{The Politics of Policy Development: The Case of an Aboriginal High School}

\section{Defining the Goals}

I begin my political analysis by defining the major goals of this debate. The goals are defined as "a central component of a policy analysis and the rational attempt to achieve objectives" (Stone, 2002, p. 37). The goals addressed are equity, liberty and security. It is important to consider that the policymaking process can determine the way in which social values such as equity, liberty and security are addressed. Each of these values contains ambiguity and different interpretations that can be linked to a politic struggle. I define these concepts with the intent to convince opponents that developing interventive policies would be in the best interest of Aboriginal youth and families.

\section{The Goal of Equity}

The first social value addressed is equity. "Equity is defined as the goals of all sides in conflict about how resources are distributed" (Stone, 2002, p. 39). There are many important dimensions to consider in a distribution analysis. I focus on the concepts that involve defining the recipients and group-based distribution. The recipients in this case are people of Aboriginal ancestry. Stone (2002) states:

\footnotetext{
The group-based distribution perspective holds that some major divisions in society are relevant to distributive equity and that membership in a group based on these divisions should sometimes outweigh individual characteristics in determining distribution. An example of a distributive preference is a policy that favors members of a certain group that have been victims of historical discrimination (p. 45).
}

I now avow that Aboriginal people are entitled to group-based distribution as compensation for historical discrimination. More specifically, due to the long-term effects of the residential school system, the government should develop policy to give Aboriginal youth a boost in distributive preference.

One example of a distributive preference would be the provision of free access to physical activities such as offered through after school sporting activities. The equity goal is to develop policies that support increased access to physical activity for the youth, and thus create a healthier environment. Sallis et al. (2001) indicated that increasing opportunities for exercise have been shown to be associated with increased physical activity levels. I recognize that this distributive preference is not direct compensation for the discrimination; however, increasing physical activity can assist in promoting healing in Aboriginal youth.

Furthermore, healing is promoted in Lee Brown High School by incorporating the teachings of the Medicine Wheel and by seeking to develop the individual as a whole (Haig-Brown et al., 1997). Moreover, "the mission emphasizes healing which nurtures the mind, body and spirit of the students" (p. 46), and both teachers and the elders indicate that there has been great success with this method (HaigBrown et al., 1997). Certainly, the environment in Lee Brown promotes not only academics but also healing, and these successes support my argument that policy should be developed to support distributive preferences to Aboriginal youth. These policies would work to promote physical activity and psychological healing while also providing recognition of the injustices of the past.

Opponents to the group-based distribution might argue that non-Aboriginal people have paid for the mistakes of the past and for the damages caused by some residential school experiences. Opponents might accept the legitimacy of group-based discrimination for compensatory purposes, but often hold that compensation has already been given to groups affected by these residential school experiences. This belief may be countered by identifying the difficulty of measuring how much compensation is adequate for years of psychological and physical abuse. It is also difficult to measure the degree of harm that has been caused to many generations of Aboriginal families. I would like to challenge the opponents to recognize the ambiguity involved in their arguments and to consider the benefits of providing the distribution preferences entailed with the equity-based goal. 


\section{The Goal of Security}

Another important value highlight by Stone (2002) is security. Security is defined as "the satisfaction of minimum human needs" (p. 37). One metaphor found within the literature describes Lee Brown School as an idealized family. The students referred to the school teachers, staff and administration as "part of the extended family" (Haig-Brown et al., 1997, p. 147). Teachers and principals often find themselves in multiple roles. The principal stated "a parent for the Aboriginal family is someone who cares for the child" (p. 46). Traditionally in the Aboriginal culture, all adults have the responsibility to serve as parents. One teacher stated "it's no different than being around my own family: there is a lot of humor and there are a lot of real heavy serious issues that we are dealing with..." (Haig-Brown et al., 1997, p. 147). The extended family, respect for one another and significant common experience bind the people in this school and contribute to a feeling of comfort and security for the students. It appears that Lee Brown promotes the value of security with the students in the school, and it is this type of environment that would support health policies designed to prevent obesity.

\section{The Goal of Liberty}

The last goal identified is liberty. Liberty is defined as the ability to "do as you wish as long as you do not harm others" (Stone, 2002, p. 37). Lee Brown High School not only provides a safe environment but also provides students with the freedom to develop strong Aboriginal identities. Haig-Brown, Hodgson-Smith, Regnier and Archibald (1997) state:

Classrooms and schools are often hostile environments where the students are misunderstood, isolated, age-grade displaced, ignored in the curriculum and taught by methods designed for non-Indian middleclass students. In other high schools the Aboriginal students have been forced to integrate, give up their identity, adopt new values and a new way of life (p.79).

Lee Brown High School offers a program of studies that affirms the contemporary world of Aboriginal people and honors the best of Aboriginal heritage. Implementing school health policies designed to prevent obesity would also work to promote a sense of liberty for the students.
All the goals identified in this analysis are suggested justifications for the government and school board to consider in supporting the development of policies that are designed to prevent obesity. I have argued that it is justified because the policy will compensate for previous discrimination and promote equity to Aboriginal peoples. It is also appropriate to establish the obesity intervention policies because Lee Brown High School promotes a strong sense of security and liberty for its students.

\section{Defining the Problem}

I plan to represent the problem from my professional point of view in order to convince families and communities of the importance of implementing health policies for the students of Lee Brown High School. Here I point to several different concepts to define the problem, which Stone (2002) calls the "languages of causes, decisions, power and interests."

\section{The Languages of Causes}

I begin this discussion by briefly considering the causes and intentional harm that the government caused with the establishment of the residential school system. Many years ago, the Department of Indian Affairs accepted the proposal to build and finance residential schools with the philosophy that Aboriginal children would best be assimilated into the dominant society when removed from the influences of their homes, families and communities (Barman, Hebert, \& McCaskill, 1999b). Assimilation was the super-ordinate value of these historic initiatives. The government established schools with the intent of eliminating Aboriginal culture. In doing so, the subsequent programs and processes caused significant harm to Aboriginal peoples, communities and their cultures.

The subsequent school system was particularly devastating to Indigenous cultures. The long-term effects of this system of schooling and assimilation will likely continue for many generations to come. Dieter (1999) found that the residential schools fostered dependence and low self- esteem, and for the majority of First Nations people living in Canada, the affects of this schooling system is intergenerationally extending through four or five generations. The Canadian Population Health Initiative (2005) found 
that, in general, Aboriginal peoples experience worse economic, social, and environmental conditions than those of non-Aboriginal people, and that six out of ten First Nation and Metis respondents identified residential schools as a significant contributor to poorer health status. Lower socio-economic status is normally associated with having a poor health profile, lower life expectancy, low levels of physical activity, decreased fruit and vegetable consumption and being overweight and obese (McMurray et al., 2000; Starfield, Riley, Witt, \& Robertson, 2002). These studies illustrate the destructive nature of the residential school system and the profound effects to the psychological, social and physical well-being of many Aboriginal peoples. Moreover, the residential system of schooling and assimilation has led to large discrepancies in income, employment levels, and consequently health disparities within this population.

Opponents may argue that forcing the children into the non-Aboriginal way of life, despite some of the negatives, resulted in success for many Aboriginal people. In spite of extended separation from family and community, educated Aboriginal people continued to take pride in their past and many graduates of the residential schools have become successful and productive in society (Barman et al., 1999b). Opponents may also argue that the cause of the increased rates of obesity among Aboriginal students of the Residential school era was an unintentional consequence (an inadvertent cause). The story of inadvertent cause is a common interpretation of poverty and lack of education (Stone, 2002). In other words, opponents may argue that the increasing obesity rates among Aboriginal youth are due to the lack of knowledge, education and finances to maintain a healthy lifestyle with regular physical activity and healthy eating. It is an advantage for opponents to claim an inadvertent cause because no persons can be held morally responsible for the obesity problems among the Aboriginal populations.

This belief may be countered by recognizing that Aboriginal people have suffered major injustices and that racism is still a major influential factor in presentday policy decisions. Addressing both the intentional harm caused by the residential schooling system and the unintentional inadvertent cause is a method of overcoming racism and achieving a just society.

\section{The Complexity of Decision-Making}

Along with the causes, it is also important to analyze the decision-making process and the structure of Lee Brown High School. Generally in schools, the principals are pivotal actors in the decision-making process, and they can also be a significant source of political influence in the development of school policy (Piazza, 1991). However, it is important to recognize that policy decisions in Lee Brown are not solely made by the principal. This school has established a policy decision group called the Liaison Committee. Haig-Brown, Hodgson-Smith, Regnier and Archibald (1997) point out that:

The Liaison Committee is made of two representatives of each of the three operators, and communicates with the ManagementCommittee made up of a Parent Council representative, the Principal and the Superintendent. Officially, the principal serves as a liaison between the Parent Council in its role as guardian of the cultural dimensions of the schools program, and the staff and the students (p. 72).

The principal's role is not to develop policy but serves more to be a liaison and advocate for the students, parents, teachers, school board and community.

Along with the school principal, the Parent Council is also involved with decision making. Haig-Brown, Hodgson-Smith, Regnier and Archibald (1997) indicate that:

The Parent Council also serves as an advocate and a "keeper of the vision" for the school. The Council is made up of a number of dedicated members of the city's Aboriginal community, and is responsible for framing guidelines for policy issues and supporting the cultural dimensions within the school. The Parent Council plans activities which contribute to the enhancement of Aboriginal identity and selects elders and other community personnel who may assist with the various programs (p. 85-6).

The Liaison Council also approves any program changes, serves in an advisory capacity for the administrators, and generally monitors the school's work in relation to members' perceptions of Aboriginal values and specific concerns (Haig-Brown et al., 1997). Lastly and more importantly, the Parent Council has been formed to make decisions in the best interest of the students in the school. 
The Lee Brown High School is uniquely designed to ensure the principal and Parent Council is included in the decision-making process. Political conflict arises when the other operators of the school attempt to make decisions that are not in the best interest of the students. The possibility exists that even though the Parent Council and principal support policies to prevent obesity, the school board could take the decision not to fund the policy initiative. The decisionmaking process could obviously evolve into a large political battle with jurisdictional implications.

\section{The Power within Policy Decisions}

When analyzing the decision processes, it is important to acknowledge all the potential powers and influences on the decisions made at the school level. Political influence is generally conceived as being a function of power and is a major factor in shaping and determining which education policy issues and initiatives get attention (Mazzoni, 1991). From previous discussion, I indicated that decision-making for Lee Brown High School is developed through collaborative processes by the Liaison Committee. However, this partnership is not without power struggles and influences. There are many examples of the push and pull of power dynamics that occur when developing educational policy in Aboriginal schools. These include jurisdiction over education, finances and curriculum development. This paper is delimited to the challenge of power of jurisdiction in educational decision-making.

Since the beginning of education for Aboriginal people, there have been political struggles over jurisdiction in the areas related to educational policy. In 1973, "the Federal Government accepted the basic goals for education in the document 'Indian Control Over Indian Education', and the two principles recognized were "parental responsibility" and "local control of education" (Barman et al., 1999b, p. 16). Since recognition of these two core educational principles there have been many schools that have been successfully administered by Aboriginal peoples (Castellano, Davis, \& Lahache, 2000). Also, there have been significant advances in the development of culturally appropriate philosophies, practices and policies (Barman et al., 1999b). Despite these documented successes, the jurisdiction over educational policy and the interpretation of the basic goals of this document remain at the center of selfdetermination over education.

Both principles recognized in the document "Indian Control over Indian Education" remain a political debate (this paper is delimited to the challenge of power of local control of education). The Minister's National Working Group on Education (2002) recognized that Aboriginal people must have a definitive role in education including decision-making, planning, implementation and evaluation of programs and policies. However, Aboriginal people feel that control of education is still limited by the imposition of provincial jurisdiction and federal financing. Barman, Hebert and McCaskill (1999a) state that "real control over education as a human development process is critical and that this can only happen if First Nations governments exercise control over education" (p. 40). In this policy case, local control of education means allowing administrators, teachers, parents as well as students of Lee Brown High School to participate in developing and implementing school health policies. The continual debate over jurisdiction could mean that even health conscious and culturally appropriate policies that are designed to prevent obesity may be politically influenced by the DIAND and the school board.

\section{Converting Political Interests}

Thus far, I have alluded to the fact that the various groups including the Liaison Committee have power in the decision making process at Lee Brown High School. It is however important to understand how to motivate the people with the power to understand the importance of supporting policy development. For the purpose of gaining support of powerful groups, it is useful to portray the issue as involving highly diffused benefits and concentrated costs (Stone, 2002 , p. 223). In order to sway the opponents to accept my conclusions, I strategically argue that the diffused benefits are not only for the students at Lee Brown High School but also for the families, friends and future students. Thompson, Gifford and Thorpe (2000) found that:

Connections to future generations is important, and Aboriginal people are cognizant of the need to change practices for the good of future generations, so behavioral change with a focus on the future is more likely to be successful than that focused on the individual (p. 741). 
Therefore, the benefits of establishing school policies that are supportive of a healthy environment can be passed onto the community and consequently to subsequent generations of Aboriginal peoples.

The concentrated costs of the policy would be charged to the school board. The school board may argue that the obesity policy initiative is too expensive and cannot be funded. In this situation it will be important to convince the school board that the policy has greater benefit than burden as the health policy would work to increase the overall health and wellbeing of many generations of Aboriginal peoples as students will likely pass on health knowledge and practices to successive offspring.

I have argued that the government caused harm intentionally to many Aboriginal people by the formation of residential schools and by accompanying assimilation ideologies. I have also identified that the representatives of the Liaison Committee work in collaboration with the principle and staff of the school to develop policies at Lee Brown. I have identified that the DIAND and the school board may decline funding health policies designed to prevent obesity for students attending Lee Brown High School, and that both hold significant powers in the decision making process. In order to win this political debate, it will be imperative that the opponents understand the subtle benefits of obesity prevention policies, which is the improved health to subsequent generations of Aboriginal people.

\section{Solutions to the Political Debate}

Using the concepts of rights, rules and incentives, I identify some strategies that may be used to structure relationships and to coordinate behaviors in order to achieve the previous identified goals.

\section{Rights of Aboriginal Peoples}

The first strategy that I discuss is rights. It is important to understand that Aboriginal people have implied substantive rights to policy initiatives. Stone (2002) defines " substantive right as specific actions or entitlements that people may claim" (p. 328). Aboriginal people have substantive rights due to promises made by the Government of Canada by virtue of the Treaties. In 1988, the Government of Canada responded to the Royal Commission on Aboriginal People with a long-term policy-based report designed to increase the quality of life of Aboriginal people. In this report, the Federal government identified the need to understand and address the legacy of past relationships with Aboriginal people. With this understanding, the government identified a vision that included a "quality of life like any other Canadian" (Minister of Indian Affairs and Northern Development, 2000, p.7). There are many other visions identified in this action plan; however, this paper focuses on the idea that in order to achieve a quality of life like any other Canadian, Aboriginal people will need policies that are designed to lessen the current health disparities that are so evident today.

One important inequality is the extreme poverty that many Aboriginal families experience on a daily basis (Canadian Population Health Initiative, 2005). Among Canadian children, the National Longitudinal Survey of Children and Youth 1998-1999 found that among children aged 2-11 years of age, those whose lived with families below the low income cut-off (LICO) were more likely to be obese (25\% prevalence) (Statistics Canada, 2002). The underlying assumption to explain the observation of the increasing rates of obesity is that poor nutrition and physical inactivity are characteristic patterns of people experiencing poverty (Canadian Population Health Initiative, 2004). While this study did not specifically include Aboriginal children, it establishes the fact that the poverty and the subsequent health disparities as a result of poverty seriously limit the quality of life for all children and youth, including Aboriginal children and youth. If the government truly wants to follow through with its vision of ensuring a quality of life for Aboriginal peoples like any other Canadian, both levels of government must move to support health policy initiatives that work to reduce the rates of poverty and health problems in Aboriginal families. Starting within the school environment at the policy development is just but one way to go about ensuring that this happens.

Opponents may argue that the rates of obesity are increasing in all populations and that the government needs to enhance programs to prevent obesity in Canada generally. To counter this argument, the prevalence rates for obesity in Canada are considered higher in the Aboriginal population than nonAboriginal people (Willows, 2005). I would also remind any opponents to the obesity policy initiative that the government has acknowledged that Aboriginal 
people have the right to health initiatives in order to achieve a quality of life like any other Canadian. Based on this information, there are two choices: (1) we can choose to ignore that Aboriginal people have a right to health initiatives and allow this problem to grow, or (2) we can assist Aboriginal communities to overcome this health challenge. I challenge the opponents to view the politics of Aboriginal rights with a different lens. This lens gives recognition to the potential benefits of such health policies for this unique population of people.

\section{Flexible vs. Precise Rules}

It is also important to evaluate the rules that govern with the school. The rule that a teacher must be present in the gymnasium when the students are participating in physical activities is one worth analyzing further. This rule was developed by the school board to ensure protection against potential liability in the case where an accident might occur. This rule, while important, may be perceived as extremely limiting and inflexible. It essentially limits student opportunities for physical activities to times when the teachers are available.

While working with the students in Lee Brown, I learned that only a small percentage of students were able to participate in organized physical activity and that there is a great potential to increase the opportunities for physical activities for the students at the school if the rule of "having a teacher present" was more flexible. A flexible rule "ensures fairness by allowing sensitivity to contextual and individual differences, allows officials to respond creatively to new situations, creates efficiency by letting officials use their knowledge of particular situations, and would symbolize the ideals and aspirations of the community" (Stone, 2002, p. 292). A flexible rule would be more suited for an Aboriginal school. The new rule would allow for sensitivity to this unique culture of people and work to promote physical activity opportunities for Aboriginal youth.

School administrators may argue that a precise rule is necessary to protect against liability and the safety of the students. A precise rule is "a rule that ensures fairness by treating likes alike, eliminates arbitrariness, and symbolizes the rule of law" (Stone, 2002, p. 292). The problem with this argument is that there are already too many inequalities among Aboriginal people that do not exist in the general population (for instance, access to health services, post-secondary education, employment training, resources, etc.). The Canadian Population Health Initiative (2005) indicates the health and economic status of Aboriginal people is significantly less than that of non-Aboriginal people. There are also distinctions between groups of Aboriginal peoples and these unique features have policy implications for research, for resources and for the improvement of Aboriginal people's health (p. 78). Culture, language and tradition are integral to the holistic view of health held by Aboriginal peoples living in Canada (Health Canada, 2003), and the application of a precise rule ignores all the unique characteristics of these populations.

Changing the provisions for who is allowed to supervise activity at the school would also open up more opportunities for physical activity for Aboriginal students. The school could potentially be opened in the evening for organized physical activities that would be offered free of charge. Having the school principal designate a parent or member of the Parent Council to supervise school activity would also provide possible opportunities for the whole community to become involved in their children's lives and would help make the connection in their minds about the importance of physical activity in relation to health.

Teachers might also argue that the parents and council members cannot provide the same degree of safety as teachers because qualified teachers have training and experience with supervising classrooms and physical activities in gym settings that most parents and community members do not have. I would like to counter this argument by proposing that the teachers or administrators provide short workshops to parents designed to educate new supervisors (parents) on the safety standards and procedures required to supervise a gym and respond to emergency circumstances. Most parents will be able to acquire these skills, just as the teachers have acquired their skills.

\section{Positive Incentives for Students}

To sum up, I would like to demonstrate how the interventive policy can produce a positive incentive in the school. As stated earlier, there are many physiological effects of obesity. Research demonstrates that there are also profound psychological effects as well. Findings show that obese children are more likely to develop an undesirable body image and poor self-esteem (Paxton, Neumark-Sztainer, 
Hannan, \& Eisenberg, 2006). In yet another study, body satisfaction decreased significantly more among younger adolescents than older adolescents, among some racial/ethnic groups of males, and among those whose BMI increased, over a five year period (Eisenberg, Neumark-Sztainer, \& Paxton, 2006). Neumark-Sztainer, Paxton, Hannan, Haines and Story (2006) found that lower body satisfaction does not serve as a motivator for engaging in healthy weight management behaviors, but rather predicts the use of behaviors that may place adolescents at risk for weight gain and poorer overall health. Developing policies that work to prevent obesity can create a positive incentive to achieve a healthier body image and greater self-esteem. Providing opportunities for physical activity and healthy eating will help to create positive leaders for our future and will encourage young Aboriginal people to believe in themselves.

\section{Future Research Implications}

Future research includes exploring the cultural, social and biological contributions to obesity in Aboriginal youth. There is also future potential to investigate culturally relevant health promotion strategies and interventions in Aboriginal high schools across Canada, and research in this area will build capacity in Aboriginal health research. This method of policy analysis may also be useful in the development and implementation of policy for Aboriginal children and youth living in care. Lastly, there is potential to explore how to more effectively educate Aboriginal parents and families on how to become involved in health policy development and implementation not just within the educational environment but in all environments for their populations.

\section{Conclusion}

There are many political factors affecting policy decisions. Over the years, Aboriginal peoples have made great effort to address social values within the policy making process. One of the problems at the center of the historical struggle of Aboriginal peoples is the fact that the colonial government established residential schools with the intent to eliminate the Aboriginal culture and, thus, has caused significant and inadvertent harm to Aboriginal peoples and subsequent generations. Another political struggle is the acceptance of Aboriginal people's right to develop educational policies as set out in the document
"Indian Control Over Indian Education". This paper encourages policy makers to understand that Aboriginal people have the right to develop health policies in the educational environment for their children and that there are many potential benefits to developing obesity prevention policies within the school setting. It has been asserted that wellconsidered policy decisions are amongst the most important contributions leaders can make to overcome racism and for achieving a more just society for the health of all Aboriginal people and their successive generations.

\section{Endnotes}

1. The term Aboriginal is a constitutionally recognized terms that generally includes Indians, Métis and Inuit peoples. The term "Indian" refers specifically to "A person who is registered or entitled to be registered in the Indian Register" of the Department of Indian Affairs and Northern Development (DIAND). For the purposes of this article, I have chosen to utilize the more generalized term "Aboriginal people" throughout the paper.

2. Stone's book, Policy Paradox: The Art of Political Decision Making (W.W. Norton, 1997, 2001 and 2002) is used in teaching programs around the world. In 2002, it won the American Political Science Association's Aaron Wildavsky Award for an Enduring Contribution to Policy Studies.

3. This is a pseudonym to protect the identity of the school. Lee Brown is an urban high school for Aboriginal youth located in what is recognized as traditional territory of the Plains Cree (Haig-Brown, Hodgson-Smith, Regnier, \& Archibald, 1997). The High School is organized and run jointly by the Parent Council, the Catholic School Board and the Department of Indian Affairs and Northern Development (DIAND), where all three groups are recognized as the operators of the school (Haig-Brown et al., 1997). The Federal government is held responsible for funding the school while the school board sets the global budget following Provincial school system budgetary procedures, while a Parent Council proposes budget priorities (Haig-Brown et al., 1997, p. 85).

4. The "Medicine Wheel" is a framework commonly used by First Nation and Aboriginal organizations to develop community based service models. The teachings of the medicine wheel provide a useful framework that some First Nations and Aboriginal organizations use to balance the requirements of provincial legislation with a deep respect for the cultural background of families and children. The medicine wheel is widely used to describe humanity as being interconnected and interdependent with one's family, community, tribe, nation and all of creation. It emphasizes the importance of balance among all aspects of one's life, beginning with a spiritual core and expanding outward to the physical, emotional, intellectual, and social realms (Shangreaux, n.d.).

\section{References}

Barman, J., Hebert, Y., \& McCaskill, D. (1999a). Indian education in Canada, Volume 2: The challenge. Vancouver: UBC Press. 
Barman, J., Hebert, Y., \& McCaskill, D. (1999b). Indian education in Canada, Volume 1: Thelegacy. Vancouver: UBC Press.

Briggs, M., Safaii, S., \& Beall, D. L. (2003). Position of the American Dietetic Association, society for nutrition education, and American school food service association-nutrition services: an essential component of comprehensive school health programs. Journal of the American Dietetic Association, 103(4), 505-514.

Canadian Population Health Initiative. (2004). Overweight and obesity in Canada: A population health perspective. Ottawa: Canadian Institute for Health Information.

Canadian Population Health Initiative. (2005). Improving the health of Canadians. Ottawa: Canadian Institute for Health Information.

Castellano, M. B., Davis, L., \& Lahache, L. (2000). Aboriginal education: Fulfilling the promise. Vancouver: UBC Press.

Cole, T. J., Bellizzi, M. C., Flegal, K. M., \& Dietz, W. H. (2000). Establishing a standard definition for child overweight and obesity worldwide: International survey. British Medical Journal, 320(7244), 1240-1243.

Cooke, M., Beavon, D., \& McHardy, M. (2004). Measuring the well-being of Aboriginal people: An application of the United Nations' human development index to Registered Indians in Canada, 1981-2001. RetrievedAugust 8th, 2007, from http:// www.ainc-inac.gc.ca/pr/ra/mwb/index e.html.

Dale, D., \& Corbin, C. B. (2000). Physical activity participation of high school graduates following exposure to conceptual or traditional physical education. Research Quarterly for Exercise and Sport, 71(1), 61-68.

Deiter, C. (1999). From our mothers' arm: The intergenerational impact of residential schools in Saskatchewan. Toronto: United Church Publishing House.

Eisenberg, M. E., Neumark-Sztainer, D., \& Paxton, S. J. (2006). Five-year change in body satisfaction among adolescents. Journal of Psychosomatic Research, 61(4), 521-527.

Evans, A. E., \& Sawyer-Morse, M. K. (2002). The right bite program: a theory-based nutrition intervention at a minority college campus. Journal of the American Dietetic Association, 102(3 Suppl), S89-93.

Haig-Brown, C., Hodgson-Smith, K. L., Regnier, R., \& Archibald, J. (1997). Making the spirit dance within. Toronto: James Lorimer \& Company Ltd.

Hanley, A. J., Harris, S. B., Gittelsohn, J., Wolever, T. M., Saksvig, B., \& Zinman, B. (2000). Overweight among children and adolescents in a Native Canadian community: Prevalence and associated factors. American Journal of Clinical Nutrition, 71(3), 693-700.

Harris, S. B., Zinman, B., Hanley, A., Gittelsohn, J., Hegele, R., Connelly, P. W., et al. (2002). The impact of diabetes on cardiovascular risk factors and outcomes in a Native Canadian population. Diabetes Research and Clinical Practice, 55(2), 165-173.

Health Canada. (2003). A statistical profile on the health of First Nations in Canada. Ottawa: Health Canada, First Nations Inuit Health Branch.

Janssen, I., Katzmarzyk, P. T., Srinivasan, S. R., Chen, W., Malina, R. M., Bouchard, C., et al. (2005). Utility of childhood BMI in the prediction of adulthood disease: Comparison of National and International references. Obesity Research, 13(6), 1106-1115.

Mazzoni, T. L. (1991). Analyzing state school policy making: An arena model. Educational Evaluation and Policy Analysis, 13, 115-138.

McMurray, R. G., Harrell, J. S., Deng, S., Bradley, C. B., Cox, L. M., \& Bangdiwala, S. I. (2000). The influence of physical activity, socioeconomic status, and ethnicity on the weight status of adolescents. Obesity Research, 8(2), 130-139.

Minister's National Working Group on Education. (2002). Our children-keepers of the sacred knowledge: Final report of the minister's national working group on education. Retrieved September 30th, 2006, from http://www.aincinac.gc.ca/ps/edu/finre/index_e.html.

Minister of Indian Affairs and Northern Development. (2000). Gathering strength-Canada's Aboriginal action plan: A progress report. Retrieved June 20th, 2007, from http://www.ainc-inac. gc.ca/gs/pdf/progr1_e.pdf. 
Neumark-Sztainer, D., Paxton, S. J., Hannan, P. J., Haines, J., \& Story, M. (2006). Does body satisfaction matter? Five-year longitudinal associations between body satisfaction and health behaviors in adolescent females and males. Journal of Adolescent Health, 39(2), 244-251.

O’Neil, C. E., \& Nicklas, T. A. (2002). Gimme 5: an innovative, school-based nutrition intervention for high school students. Journal of the American Dietetic Association, 102 (3 Suppl), S93-96.

Paxton, S. J., Neumark-Sztainer, D., Hannan, P. J., \& Eisenberg, M. E. (2006). Body dissatisfaction prospectively predicts depressive mood and low self-esteem in adolescent girls and boys. Journal of Clinical Child and Adolescent Psychology, 35(4), 539-549.

Piazza, M. M. (1991). The politics of Principalship. Politics of Education Bulletin, 3, 8.

Ritenbaugh, C., Teufel-Shone, N. I., Aickin, M. G., Joe, J. R., Poirier, S., Dillingham, D. C., et al. (2003). A lifestyle intervention improves plasma insulin levels among Native American high school youth. Preventive Medicine, 36(3), 309-319.

Sallis, J. F., Conway, T. L., Prochaska, J. J., McKenzie, T. L., Marshall, S. J., \& Brown, M. (2001). The association of school environments with youth physical activity. American Journal of Public Health, 91(4), 618-620.

Schwimmer, J. B., Burwinkle, T. M., \& Varni, J. W. (2003). Health-related quality of life of severely obese children and adolescents. Journal of the American Medical Association, 289(14), 1813-1819.

Shangreaux, C. (n.d.). Integrating Medicine Wheel Teachings Into First Nations \& Aboriginal Child Welfare Practice. Winnipeg, MB: Animikii Ozoson Child and Family Services.

Starfield, B., Riley, A. W., Witt, W. P., \& Robertson, J. (2002). Social class gradients in health during adolescence. Journal of Epidemiology and Community Health, 56(5), 354-361.

Statistics Canada. (2002). National longitudinal survey of children and youth: Childhood obesity, 1994-1999. Retrieved August 8th, 2007, from http://www.statcan.ca/cgi-bin/imdb/p2SV.pl?Fun ction $=$ getSurvey $\&$ SDDS $=4450 \&$ lang $=$ en $\& d b=\mathrm{I}$

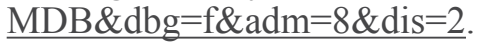

Stone, D. (2002). Policy Paradox: The art of political decision making. New York, London: W.W Norton \& Company Inc.

Tremblay, M. S., Katzmarzyk, P. T., \& Willms, J. D. (2002). Temporal trends in overweight and obesity in Canada, 1981-1996. International Journal of Obesity and Related Metabolic Disorders, 26(4), 538-543.

Willows, N. (2005). Overweight in First Nation children: Prevalence, implications and solutions. Journal of Aboriginal Health, 2, 76-83.

Young, T. K., Dean, H. J., Flett, B., \& Wood-Steiman, P. (2000). Childhood obesity in a population at high risk for type 2 diabetes. Journal of Pediatrics, 136(3), 365-369. 